\title{
Context-Awareness Healthcare for Disease Reasoning Based on Fuzzy Logic
}

\author{
Byung-Kwan Lee*, Eun-Hee Jeong ${ }^{\dagger}$ and Sang-Sik Lee**
}

\begin{abstract}
This paper proposes Context-Awareness Healthcare for Disease Reasoning based on Fuzzy Logic. It consists of a Fuzzy-based Context-Awareness Module (FCAM) and a Fuzzy-based Disease Reasoning Module (FDRM). The FCAM computes a Correlation coefficient and Support between a Condition attribute and a Decision attribute and generates Fuzzy rules by using just the Condition attribute whose Correlation coefficient and Support are high. According to the result of accuracy experiment using a SIPINA mining tool, those generated by Fuzzy Rule based on Correlation coefficient and Support (FRCS) and Improved C4.5 are 0.84 and 0.81 each average. That is, compared to the Improved C4.5, the FRCS reduces the number of generated rules, and improves the accuracy of rules. In addition, the FDRM can not only reason a patient's disease accurately by using the generated Fuzzy Rules and the patient disease information but also prevent a patient's disease beforehand.
\end{abstract}

Keywords: Fuzzy-based context-awareness module(FCAM), Fuzzy-based disease reasoning module (FDRM), Fuzzy set, Fuzzy rules, Context-awareness information, Correlation coefficient, Support

\section{Introduction}

IT technologies such as Internet, Mobile, and Ubiquitous are now changing the paradigm of medical care from provider-oriented medicine to user-oriented medicine, from treatment medicine to preventive medicine, and from disease-oriented medicine to wellbeing-oriented medicine. Thanks to them, medical customers can be diagnosed at an early stage of disease with mobile devices that are connected to computers at any time or anywhere. For this, health care providers are doing a lot of researches on individually-customized medical service to provide their customers with the best medical service.

In particular, Data Mining Technique was used to analyze the medical information of a patient's systemic lupus erythematosus in the RX project of Stanford University in the 1980's [1]. Since then, Data Mining technique using machine learning has been applied to many fields of medical diagnosis such as thyrotoxic myopathy [2-4], rheumarthritis [5], cardiovascular diseases [6], Neuropsychosis [7], etc [8].

This paper proposes Context-Awareness Healthcare for Disease Reasoning based on Fuzzy Logic. It consists of the Fuzzy-based Context-Awareness Module (FCAM) and the Fuzzy-based Disease Reasoning Module (FDRM).

The FCAM fuzzifies disease information, manages a patient's health condition by collecting the context-

$\dagger$ Corresponding Author: Dept. of Regional Economics, Kangwon National University, Korea. (jeongeh@kangwon.ac.kr)

* Dept. of Computer Engineering, Catholic Kwandong University, Korea. (bklee@ cku.ac.kr)

** Dept. of Biomedical Engineering, Catholic Kwandong University, Korea. (lsskyj@cku.ac.kr)

Received: June 23, 2015; Accepted: November 3, 2015 awareness information such as a patient's physiological information, medical record, family history in real time, and generates the fuzzy rules on a disease. The FDRM reasons a disease with the Fuzzy rules and a patient's Context-Awareness information collected in the FCAM accurately and prevents a patient from an unexpected disease beforehand.

The remainder of this paper is organized as follows. Section 2 discusses the related works on a Fuzzy Logic System and C4.5. Section 3 shows the Context-Awareness Module and Disease Reasoning based on Fuzzy Logic. Section 4 shows the estimation result and finally in section 5 , we describe our conclusions.

\section{Related works}

\subsection{Fuzzy logic system}

"Fuzzy Logic" was introduced with the 1965 proposal of fuzzy set theory by Lotfi A. Zadeh [9]. The Fuzzy Logic has been applied to many fields, from control theory to artificial intelligence.

Specially, a Fuzzy Logic System can be defined as the nonlinear mapping of an input data set to a scalar output

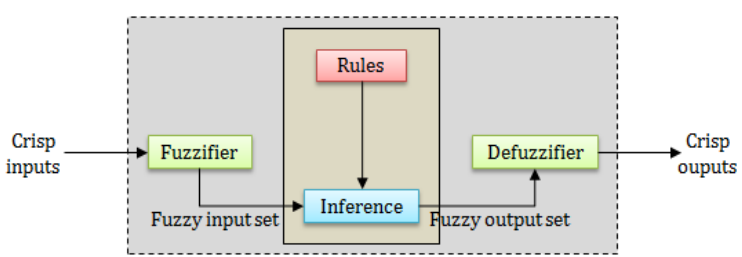

Fig. 1. A Fuzzy logic system 
data [10, 11]. A Fuzzy Logic System consists of four main parts: fuzzifier, rules, inference engine, and defuzzifier. The general architecture of a Fuzzy Logic System is shown in Fig. 1.

The process of a Fuzzy Logic system is explained in Algorithm 1[9].

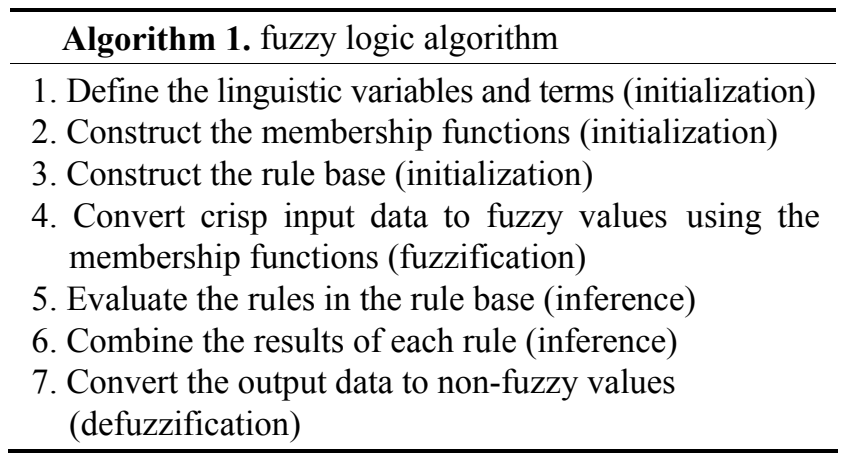

\subsubsection{Linguistic variables}

Linguistic variables are the input or output variables of the Fuzzy Logic System whose values are words or sentences from natural language, instead of numerical values. For example in the Fuzzy Logic System the linguistic variables are expressed as follows according to a patient's temperature.

$$
\begin{aligned}
\text { temperature }(\mathrm{t})= & \{\text { hypothermia, normothermia, } \\
& \text { mild fever, high fever }\}
\end{aligned}
$$

\subsubsection{Membership function}

Membership functions are used in the fuzzification and defuzzification steps of the Fuzzy Logic System. Membership functions can have several different shapes such as Fig. 2 [9-11].

The most commonly used shapes are triangular, trapezoidal, Gaussian and bell shaped membership function.

This paper uses triangular, trapezoidal, and singleton membership function for a patient's disease reasoning.

\subsubsection{Fuzzification}

A Fuzzy Logic system uses linguistic variables instead

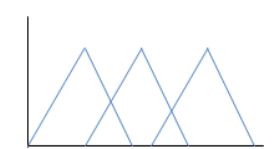

(a) Triangular

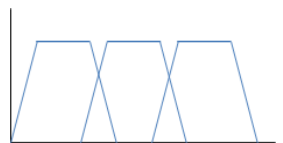

(b) Trapezoidal

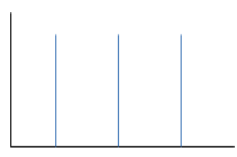

(c) Singleton

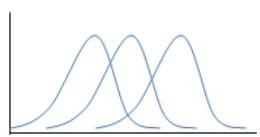

(d) Gaussian

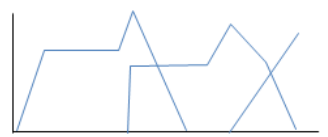

(e) Piecewise linear
Fig. 2. Membership functions of numerical variables. The process of converting a numerical variable (real number or crisp variable) to a linguistic variable (fuzzy number) is called fuzzification. The simplest form of membership function is triangular membership function.

\subsubsection{Defuzzification}

The reverse fuzzification is called defuzzification. The use of a Fuzzy Logic System inference engine produces the output in a linguistic form. According to real world requirements, the linguistic variables have to be transformed to crisp output. Weighted average method is the best wellknown defuzzification method for Sugeno type fuzzy controller [12, 13].

This paper produces a patient's disease reasoning result in this weighted average method.

\subsection{Context-awareness}

Context-awareness is defined by Brown [14], Ryan [15], and Dey [16].

Brown et al. [14] defines context as location, identities of the people around a user, the time of day, season, temperature, etc. Ryan [15] defines context as a user's location, environment, identity and time. Dey [16] enumerates context as the user's emotional state, focus of attention, location and orientation, date and time, objects, and people in a user's environment [17].

This paper defines Context-Awareness as a patient's physiological information, personal information, medical record, and family history.

In addition, it provides a patient's disease accurately by combining Fuzzy Theory such as Fuzzy Set, Fuzzy Rule, etc with the Context-Awareness information.

\subsection{C4.5 algorithm}

C4.5 is an algorithm used to generate a decision tree developed by Ross Quinlan [18, 19]. C4.5 is an extension of Quinlan's earlier ID3 algorithm. The decision trees generated by $\mathrm{C} 4.5$ can be used for classification, and for this reason, $\mathrm{C} 4.5$ is often referred to as a statistical classifier [20].

In general, the steps in $\mathrm{C} 4.5$ algorithm to build decision tree are $[21,22]$ :

- Choose attribute for root node

- Create branch for each value of that attribute

- Split case according to branches

- Repeat process for each branch until all cases in the branch have the same class.

Choosing which attribute to be a root is based on highest gain of each attribute. To count the gain, formula (1) is used to count the gain $[21,22]$. 


$$
\operatorname{Gain}(\mathrm{S}, \mathrm{A})=\operatorname{Entropy}(\mathrm{S})-\sum_{\mathrm{i}=1}^{\mathrm{n}} \frac{\left|\mathrm{S} \mathrm{S}_{\mathrm{i}}\right|}{|\mathrm{S}|} \times \operatorname{Entropy}\left(\mathrm{S}_{\mathrm{i}}\right)
$$

Here, $\left\{\mathrm{S}_{1}, \ldots, \mathrm{S}_{\mathrm{i}}, \ldots, \mathrm{S}_{\mathrm{n}}\right\}$ the partitions of $\mathrm{S}$ according to values of attribute $A$.

$\mathrm{n}$ is the number of attributes A.

$\left|\mathrm{S}_{\mathrm{i}}\right|$ is the number of cases in the partition $\mathrm{S}_{\mathrm{i}}$.

$|\mathrm{S}|$ is the total number of cases in $\mathrm{S}$.

The entropy is gotten by formula (2) [21, 22].

$$
\operatorname{Entropy}(\mathrm{S})=\sum_{\mathrm{i}=1}^{\mathrm{n}}-\mathrm{P}_{\mathrm{i}} \times \log _{2} \mathrm{p}_{\mathrm{i}}
$$

Here, $\mathrm{S}$ is case set, and $\mathrm{n}$ is the number of cases in the partitions $\mathrm{S} . \mathrm{P}_{\mathrm{i}}$ is the Proportion of $\mathrm{S}_{\mathrm{i}}$ to $\mathrm{S}$.

\section{Context-Awareness Healthcare for Disease Reasoning based on Fuzzy Logic}

The "Context-Awareness Healthcare for Disease Reasoning based on Fuzzy Logic" proposed in this paper consists of a Fuzzy-based Context-Awareness Module (FCAM) and a Fuzzy-based Disease Reasoning Module (FDRM). Its total structure and data flow are shown in Fig. 3.

\subsection{Overview}

The Fuzzy-based Context-Awareness Module (FCAM) fuzzifies all the disease information beforehand, generates Fuzzy Rules with the disease information and collects the Context-Awareness information such as physiological information, medical records, personal information, and family history to check a patient's current health condition. Then, it judges a patient's disease after comparing the fuzzified disease information with a patient's Context-

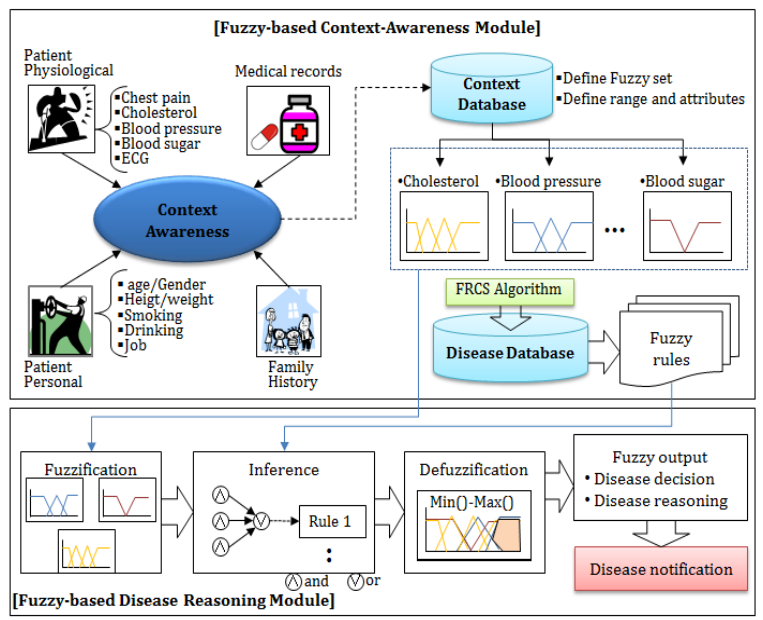

Fig. 3. The total structure and data flow
Awareness information.

In particular, when it generates Fuzzy Rules, it not only decreases the number of conditions within a rule by excluding the condition attributes whose Correlation coefficient and Support is the lowest about elements but also improves the accuracy of disease reasoning with the better accuracy of rules.

The Fuzzy-based Disease Reasoning Module (FDRM) reasons a patient's disease accurately by using the Fuzzy Rules and the Context-Awareness information collected in the FCAM and then prevents a patient from an unexpected disease by informing them of the result.

\subsection{Fuzzy-based context-awareness module (FCAM) design}

The FCAM collects a patient's Context-Awareness information and classifies it into the following 4 categories.

- A patient's physiological information such as chest pain, cholesterol level, blood sugar, blood pressure, ECG, etc

- A patient's medical records

- A patient's personal information such as age, weight, height, smoking, drinking, job, etc.

- A patient's family history

\begin{tabular}{|c|c|c|}
\hline Fuzzy set & Range & linguistic variables \\
\hline Chest pain & $\begin{array}{l}1 \\
2 \\
3 \\
4\end{array}$ & $\begin{array}{l}\text { typical angina } \\
\text { atypical angina } \\
\text { non angina } \\
\text { asymptomatic }\end{array}$ \\
\hline Cholesterol & $\begin{array}{c}<197 \\
188-250 \\
217-307 \\
>281 \\
\end{array}$ & $\begin{array}{c}\text { low } \\
\text { medium } \\
\text { high } \\
\text { very high }\end{array}$ \\
\hline Blood pressure & $\begin{array}{c}<134 \\
124-153 \\
142-172 \\
>154 \\
\end{array}$ & $\begin{array}{l}\text { low } \\
\text { medium } \\
\text { high } \\
\text { very high }\end{array}$ \\
\hline Blood sugar & $\begin{array}{l}<120 \\
>=120\end{array}$ & $\begin{array}{c}\text { no } \\
\text { yes } \\
\end{array}$ \\
\hline $\begin{array}{c}\text { ECG } \\
\text { (ST_depression) }\end{array}$ & $\begin{array}{c}<0.4 \\
0.4-1.8 \\
>1.8\end{array}$ & $\begin{array}{c}\text { normal } \\
\text { abnormal } \\
\text { hypertrophy }\end{array}$ \\
\hline Thallium & $\begin{array}{l}3 \\
6 \\
7\end{array}$ & $\begin{array}{c}\text { Normal } \\
\text { Fixed Defect } \\
\text { Reversible Defect }\end{array}$ \\
\hline Age & $\begin{array}{c}<38 \\
33-45 \\
40-58 \\
>52\end{array}$ & $\begin{array}{c}\text { young } \\
\text { mid } \\
\text { old } \\
\text { very old }\end{array}$ \\
\hline Gender & $\begin{array}{l}1 \\
0 \\
\end{array}$ & $\begin{array}{c}\text { male } \\
\text { female }\end{array}$ \\
\hline smoking year & $\begin{array}{l}<=30 \\
>30\end{array}$ & $\begin{array}{l}\text { low } \\
\text { high }\end{array}$ \\
\hline drinking & $\begin{array}{l}0 \\
1\end{array}$ & $\begin{array}{c}\text { no } \\
\text { yes }\end{array}$ \\
\hline $\begin{array}{c}\text { Family history } \\
\text { (diabetes, } \\
\text { hypertension, ...) }\end{array}$ & $\begin{array}{c}<1 \\
>=1\end{array}$ & $\begin{array}{l}\text { no } \\
\text { yes }\end{array}$ \\
\hline $\begin{array}{l}\text { Medical records } \\
\text { (diabetes, ...) }\end{array}$ & $\begin{array}{c}<1 \\
>=1\end{array}$ & $\begin{array}{l}\text { no } \\
\text { yes }\end{array}$ \\
\hline
\end{tabular}

Table 1. Fuzzy set, range, and linguistic variables 
Besides, the FCAM defines Fuzzy Set, data range and linguistic variables about each element with the collected Context-Awareness information in Table $1[23,24]$.

Fig. 4 shows the membership function and fuzzification of cholesterol [24].

Fig. 5 shows the procedure in which the FCAM is processed.

To begin with, the FCAM collects a patient's ContextAwareness information in real time, judges the patient's health condition by using Table1, and informs the patient

$$
\begin{gathered}
\mu_{\text {low }}(x)=\left\{\begin{array}{cc}
1 & x<151 \\
\frac{197-x}{46} & 151<x<197
\end{array}\right\} \\
\mu_{\text {medium }}(x)=\left\{\begin{array}{cc}
\frac{(x-188)}{27} & 188<x<215 \\
1 & x=215 \\
\frac{250-x}{35} & 215<x<250
\end{array}\right\} \\
\mu_{\text {high }}(x)=\left\{\begin{array}{cc}
\frac{(x-217)}{46} & 217<x<263 \\
1 & x=263 \\
\frac{307-x}{44} & 263<x<307
\end{array}\right\} \\
\mu_{\text {veryhigh }}(x)=\left\{\begin{array}{cc}
\frac{(x-281)}{66} & 281<x<347 \\
1 & x \geq 347
\end{array}\right\}
\end{gathered}
$$

(a) Membership function

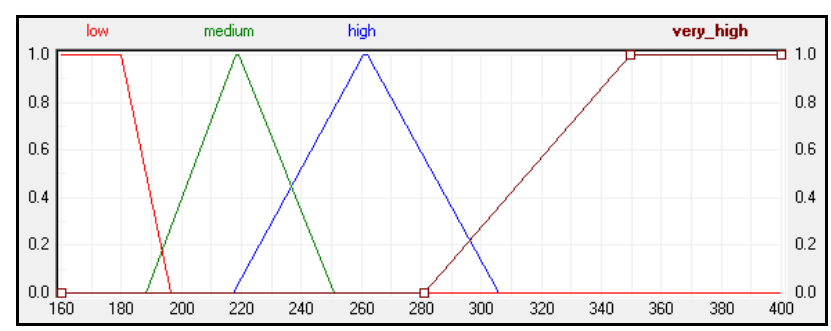

(b) fuzzification

Fig. 4. Fuzzification and membership function

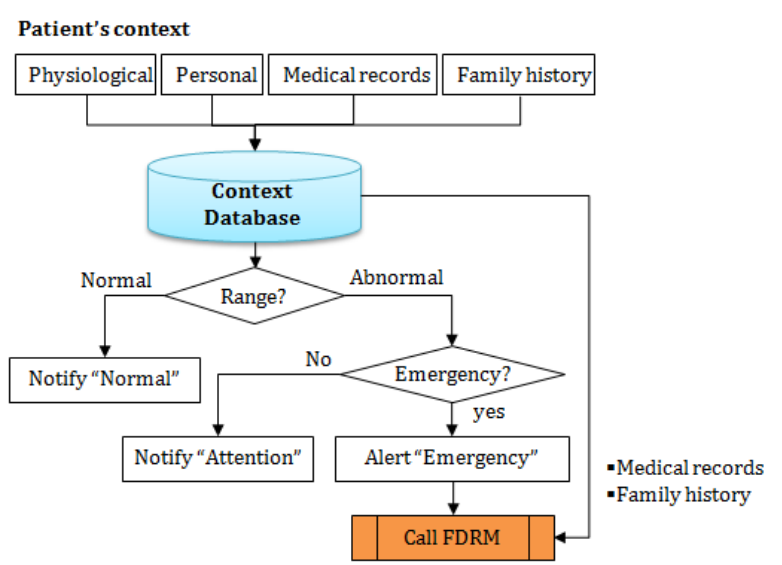

Fig. 5. The procedure of FCAM of the result. At this time, if the patient's health condition is abnormal, the FCAM transfers the patient's family history and medical records to the FDRM so that the FDRM can reason the patient's disease.

For example, Bob has blood pressure 150 and both of his parents suffer from high cholesterol and diabetes. When the FCAM receives such cholesterol information about Bob, it judges his health condition as "abnormal" because the "linguistic variable in Table1 is "high". Therefore, because his health condition is abnormal, the FCAM transfers a "attention: message" to him and the information on the his medical records and family history to the FDRM.

\subsubsection{Fuzzy rule generation}

The FRCS (Fuzzy Rule based on Correlation coefficient and Support) algorithm proposed in this paper generates Fuzzy Rules by using the disease information stored in the database. At this time, the FRCS algorithm computes the Correlation coefficient and Support about a Decision Attribute and a Condition Attribute. Then, because the FRCS selects the Condition Attribute which has the highest Correlation coefficient and Support, it not only reduces the number of conditions within rules, but also improves the accuracy of rules.

Algorithm 2 shows the flow of the FRCS algorithm.

Algorithm 2. FRCS algorithm

1. Input disease information.

2. Calculate the Correlation Coefficient (CC) between a Condition attributes and a Decision attribute.

$\mathrm{CC}=$ Correlation $($ a Condition. attribute, a

Decision.attribute)

3. A Condition attribute with the highest correlation coefficient becomes a condition rule.

4. Calculate the support of a Decision attribute value. Support $=$ $\begin{cases}\frac{n(y)}{n(y)+n(n)}, & \text { if a Decision attribute value is } y \\ \frac{n(n)}{n(y)+n(n)}, & \text { if a Decision attribute value is } n\end{cases}$

5. A Condition attribute with the highest support becomes a condition rule.

6.if $\min$ (support) $>0.35$ ) then

Go to 2 .

else

Make fuzzy rules of attributes

Save fuzzy rules in database end if

The following example shows that the FCAM generates Fuzzy Rules by using the FRCS algorithm and Heart Disease [24]. Table 2 shows the attributes of Heart Disease data and Fig. 6 shows its experimental data. 
Table 2. The attributes of Heart Disease and statistical values

\begin{tabular}{c|c|c|c}
\hline \multirow{2}{*}{$\begin{array}{c}\text { Field } \\
\text { Name }\end{array}$} & Description & \multicolumn{2}{c}{ Statistical values } \\
\cline { 3 - 4 } & Age & Average & $\begin{array}{c}\text { Standard } \\
\text { deviation }\end{array}$ \\
\hline a1 & Gender(1=male, 0=female) & - & 9.1 \\
\hline a2 & chest pain type & 3.2 & - \\
\hline a3 & blood pressure & 131 & 17.8 \\
\hline a4 & serum cholesterol in mg/dL & 250 & 51.5 \\
\hline a5 & $\begin{array}{c}\text { fasting blood sugar } \\
(0=\text { false, } 1=\text { true })\end{array}$ & - & - \\
\hline a6 & ECG results & 1 & 1 \\
\hline a7 & maximum heart rate & 150 & 23.1 \\
\hline a8 & $\begin{array}{c}\text { exercise induced angina } \\
(0=\text { no, } 1=y e s)\end{array}$ & - & - \\
\hline a9 & ST depression & 1.05 & 1.14 \\
\hline a10 & the slope of ST segment & 1.59 & 0.61 \\
\hline a11 & number of major vessels & 0.67 & 0.94 \\
\hline a12 & Thallium & 4.7 & 1.93 \\
\hline a13 & Class(n=absent, y=present $)$ & - & - \\
\hline a14 & & &
\end{tabular}

\begin{tabular}{|c|c|c|c|c|c|c|c|c|c|c|c|c|c|}
\hline \multicolumn{13}{|c|}{ Condition attributes } & ibutes \\
\hline a1 & a2 & a3 & a4 & a5 & a6 & a7 & a8 & a9 & a10 & a11 & a12 & a13 & a14 \\
\hline 70 & 1 & 4 & 130 & 322 & 0 & 2 & 109 & 0 & 2.4 & 2 & 3 & 3 & $y$ \\
\hline 67 & 0 & 3 & 115 & 564 & 0 & 2 & 160 & 0 & 1.6 & 2 & 0 & 7 & $\mathrm{n}$ \\
\hline 57 & 1 & 2 & 124 & 261 & 0 & 0 & 141 & 0 & 0.3 & 1 & 0 & 7 & $y$ \\
\hline 64 & 1 & 4 & 128 & 263 & 0 & 0 & 105 & 1 & 0.2 & 2 & 1 & 7 & $\mathrm{n}$ \\
\hline 74 & 0 & 2 & 120 & 269 & 0 & 2 & 121 & 1 & 0.2 & 1 & 1 & 3 & $\mathrm{n}$ \\
\hline 65 & 1 & 4 & 120 & 177 & 0 & 0 & 140 & 0 & 0.4 & 1 & 0 & 7 & $n$ \\
\hline & $\bar{E}$ & 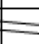 & & & $=$ & $=$ & 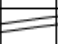 & & & & $\bar{E}$ & $\widetilde{F}$ & \\
\hline 56 & 1 & 3 & 130 & 256 & 1 & 2 & 142 & 1 & 0.6 & 2 & 1 & 6 & $y$ \\
\hline 59 & 1 & 4 & 110 & 239 & 0 & 2 & 142 & 1 & 1.2 & 2 & 1 & 7 & $y$ \\
\hline
\end{tabular}

Fig. 6. Experimental data (information table)

(1) The attribute selection of Fuzzy Rule

The FCAM selects Fuzzy rule's attributes by computing the Correlation coefficient and Support of each attribute with the FRCS algorithm.

[The $1^{\text {st }}$ step] The FCAM classifies the value of a Decision attribute (a14) into no or yes and computes a Correlation coefficient and Support about each attribute.

At this time, the FCAM computes the Correlation Coefficient and Support by using the expression (3) and (4). Table 3 shows the result of the Correlation Coefficient and Support.

$$
\mathrm{CC}=\text { Correlation }(\mathrm{CA}, \mathrm{DA})
$$

$S=\left\{\begin{array}{l}\frac{n(y)}{n(y)+n(n)}, \text { if a Decision attribute value is } y \\ \frac{n(n)}{n(y)+n(n)}, \text { if a Decision attribute value is } n\end{array}\right.$

Here, CC is Correlation Coefficient, S Support, CA Condition Attribute, DA Decision Attribute.

For example, the number of data which is a $1<60$ among 270 experimental data is 186 . The number of data whose
Table 3. The Conditional support of each attribute

\begin{tabular}{|c|c|c|c|c|c|c|c|c|}
\hline Attribute & \multicolumn{2}{|c|}{ a1 } & \multicolumn{2}{|c|}{$\mathrm{a} 2$} & \multicolumn{2}{|c|}{ a3 } & \multicolumn{2}{|c|}{ a4 } \\
\hline Correlation & \multicolumn{2}{|c|}{0.212} & \multicolumn{2}{|c|}{0.298} & \multicolumn{2}{|c|}{0.417} & \multicolumn{2}{|c|}{0.155} \\
\hline Condition & \multicolumn{2}{|c|}{$<60$} & \multicolumn{2}{|c|}{$=0$} & \multicolumn{2}{|c|}{$<=3$} & \multicolumn{2}{|c|}{$<120$} \\
\hline $\mathrm{Y}$ & 72 & 0.39 & 20 & 0.23 & 29 & 0.21 & 20 & 0.35 \\
\hline $\mathrm{N}$ & 114 & 0.61 & 67 & 0.77 & 112 & 0.79 & 37 & 0.65 \\
\hline Condition & \multicolumn{2}{|c|}{ 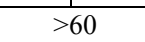 } & \multicolumn{2}{|c|}{$=1$} & \multicolumn{2}{|c|}{$>3$} & \multicolumn{2}{|c|}{$>=120$} \\
\hline $\mathrm{Y}$ & 48 & 0.57 & 100 & 0.55 & 91 & 0.71 & 100 & 0.47 \\
\hline $\mathrm{N}$ & 36 & 0.43 & 83 & 0.45 & 38 & 0.29 & 113 & 0.53 \\
\hline Attribute & \multicolumn{2}{|c|}{$\mathrm{a} 5$} & \multicolumn{2}{|c|}{$\mathrm{a} 6$} & \multicolumn{2}{|c|}{ a7 } & \multicolumn{2}{|c|}{$\mathrm{a} 8$} \\
\hline Correlation & \multicolumn{2}{|c|}{0.118} & \multicolumn{2}{|c|}{-0.016} & \multicolumn{2}{|c|}{0.182} & \multicolumn{2}{|c|}{-0.419} \\
\hline Condition & \multicolumn{2}{|c|}{$<210$} & \multicolumn{2}{|c|}{$=0$} & \multicolumn{2}{|c|}{$<2$} & \multicolumn{2}{|c|}{$<140$} \\
\hline $\mathrm{Y}$ & 19 & 0.33 & 103 & 0.45 & 47 & 0.35 & 55 & 0.71 \\
\hline $\mathrm{N}$ & 39 & 0.67 & 127 & 0.55 & 86 & 0.65 & 22 & 0.29 \\
\hline Condition & \multicolumn{2}{|c|}{$>=210$} & & & & & & 140 \\
\hline $\mathrm{Y}$ & 101 & 0.48 & 17 & 0.43 & 73 & 0.53 & 65 & 0.34 \\
\hline $\mathrm{N}$ & 111 & 0.52 & 23 & 0.58 & 64 & 0.47 & 128 & 0.66 \\
\hline Attribute & & & & & & & & 12 \\
\hline Correlation & & 19 & & & & & & 155 \\
\hline Condition & & 0 & & & & & & 1 \\
\hline $\mathrm{Y}$ & 54 & 0.30 & 67 & 0.33 & 32 & 0.25 & 40 & 0.25 \\
\hline $\mathrm{N}$ & 127 & 0.70 & 136 & 0.67 & 98 & 0.75 & 120 & 0.75 \\
\hline Condition & & & & & & & & $=1$ \\
\hline $\mathrm{Y}$ & 66 & 0.74 & 53 & 0.79 & 88 & 0.63 & 80 & 0.73 \\
\hline $\mathrm{N}$ & 23 & 0.26 & 14 & 0.21 & 52 & 0.37 & 30 & 0.27 \\
\hline Attribute & & 3 & & & & & & \\
\hline Correlation & & 25 & & & & & & \\
\hline Condition & & $=4$ & & & & & & \\
\hline $\mathrm{Y}$ & 33 & 0.22 & & & & & & \\
\hline $\mathrm{N}$ & 119 & 0.78 & & & & & & \\
\hline Condition & & 4 & & & & & & \\
\hline $\mathrm{Y}$ & 87 & 0.74 & & & & & & \\
\hline $\mathrm{N}$ & 31 & 0.26 & & & & & & \\
\hline
\end{tabular}

Decision attribute (a14) is "YES" and "NO" among the 186 is 72 and 114 each. At this time the Support of "YES" by using expression (4) is $72 /(72+114)=0.39$.

[The $2^{\text {nd }}$ step] The FCAM selects as a Condition attribute of Fuzzy rules the attribute whose correlation coefficient and support is the highest. For example, because a13 meets this condition, it is selected as the condition of Fuzzy rules.

With these selected attributes, Correlation coefficient and Support are computed in the generation step of Fuzzy Rules repeatedly and only the attributes whose Correlation coefficient and Support are high are used as a Fuzzy Rule in the FCAM.

(2) Fuzzy Rule Generation

The FCAM computes the Correlation coefficient and Support about a Condition attribute with the selected attributes and decides the order of rule conditions about each Fuzzy Rules.

The FCAM generates the condition of Fuzzy rules with the attributes the FRCS algorithm is satisfied with.

[The $1^{\text {st }}$ step] The FCAM selects as the condition of Fuzzy rules the attributes whose Correlation coefficient is the highest. That is, because a13 meets this condition in the Table 3, it is selected as the condition of Fuzzy rules. 
Table 4. The result of correlation coefficient and support

\begin{tabular}{|c|c|c|c|c|c|c|c|c|}
\hline Attribute & \multicolumn{2}{|c|}{ a1 } & \multicolumn{2}{|c|}{$\mathrm{a} 2$} & \multicolumn{2}{|c|}{ a3 } & \multicolumn{2}{|c|}{ a4 } \\
\hline Correlation & \multicolumn{2}{|c|}{0.284} & \multicolumn{2}{|c|}{0.226} & \multicolumn{2}{|c|}{0.279} & \multicolumn{2}{|c|}{0.062} \\
\hline Condition & \multicolumn{2}{|c|}{$<60$} & \multicolumn{2}{|c|}{$=0$} & \multicolumn{2}{|c|}{$<=3$} & \multicolumn{2}{|c|}{$<120$} \\
\hline $\mathrm{y}$ & 15 & 0.14 & 9 & 0.12 & 10 & 0.10 & 10 & 0.27 \\
\hline $\mathrm{n}$ & 91 & 0.86 & 65 & 0.88 & 91 & 0.90 & 27 & 0.73 \\
\hline Condition & \multicolumn{2}{|c|}{$>=60$} & \multicolumn{2}{|c|}{$=1$} & \multicolumn{2}{|c|}{$>3$} & \multicolumn{2}{|c|}{$>=120$} \\
\hline $\mathrm{y}$ & 18 & 0.39 & 24 & 0.31 & 23 & 0.45 & 23 & 0.20 \\
\hline $\mathrm{n}$ & 28 & 0.61 & 54 & 0.69 & 28 & 0.55 & 92 & 0.80 \\
\hline Attribute & \multicolumn{2}{|c|}{ a5 } & \multicolumn{2}{|c|}{ a6 } & \multicolumn{2}{|c|}{ a7 } & \multicolumn{2}{|c|}{ a8 } \\
\hline Correlation & \multicolumn{2}{|c|}{0.136} & \multicolumn{2}{|c|}{-0.016} & \multicolumn{2}{|c|}{0.186} & \multicolumn{2}{|c|}{-0.388} \\
\hline Condition & \multicolumn{2}{|c|}{$<210$} & \multicolumn{2}{|c|}{$=0$} & \multicolumn{2}{|c|}{$<2$} & \multicolumn{2}{|c|}{$<140$} \\
\hline $\mathrm{y}$ & 5 & 0.15 & 29 & 0.22 & 11 & 0.14 & 14 & 0.47 \\
\hline $\mathrm{n}$ & 28 & 0.85 & 103 & 0.78 & 65 & 0.86 & 16 & 0.53 \\
\hline Condition & \multicolumn{2}{|c|}{$>=210$} & & & & $=2$ & & \\
\hline $\mathrm{y}$ & 28 & 0.24 & 4 & 0.20 & 22 & 0.29 & 19 & 0.16 \\
\hline $\mathrm{n}$ & 91 & 0.76 & 16 & 0.80 & 54 & 0.71 & 103 & 0.84 \\
\hline Attribute & & & & & & 11 & & \\
\hline Correlation & & & & & & 44 & & \\
\hline Condition & & & & & & $=1$ & & \\
\hline $\mathrm{y}$ & 19 & 0.16 & 21 & 0.16 & 12 & 0.13 & 12 & 0.11 \\
\hline $\mathrm{n}$ & 103 & 0.84 & 110 & 0.84 & 82 & 0.87 & 95 & 0.89 \\
\hline Condition & & & & & & 1 & & \\
\hline $\mathrm{y}$ & 14 & 0.47 & 12 & 0.57 & 21 & 0.36 & 21 & 0.47 \\
\hline $\mathrm{n}$ & 16 & 0.53 & 9 & 0.43 & 37 & 0.64 & 24 & 0.53 \\
\hline Attribute & & & & & & & & \\
\hline Correlation & & & & & & & & \\
\hline Condition & & & & & & & & \\
\hline $\mathrm{y}$ & 33 & 0.22 & & & & & & \\
\hline $\mathrm{n}$ & 119 & 0.78 & & & & & & \\
\hline Condition & & & & & & & & \\
\hline $\mathrm{y}$ & 0 & 0 & & & & & & \\
\hline $\mathrm{n}$ & 0 & 0 & & & & & & \\
\hline
\end{tabular}

[The $2^{\text {nd }}$ step] The FCAM arranges the experimental data on the basis of the attributes selected in the $1^{\text {st }}$ step and computes the Support about each attribute with the expression (4).

For example, the FCAM extracts just the data whose attributes are a13<4. Consequently, the FCAM extracts 152 data and computes the Correlation Coefficient and Support with expression (3) and (4). The Table 4 shows the result of the $2^{\text {nd }}$ step.

[The $3^{\text {rd }}$ step] The FCAM selects as Fuzzy rules the attributes whose Support in the $2^{\text {nd }}$ step is highest. That is, the FCAM selects as the condition of Fuzzy rules the a3 whose Support is 0.90 .

Fig. 7 shows an example of the Fuzzy Rules generated by the FCAM. Its Fuzzy Rules in Fig. 7 can have several rule conditions and each rule condition can be called the $1^{\text {st }}$ rule condition, the $2^{\text {nd }}$ rule condition, etc according to each location.

[The $4^{\text {th }}$ step] The FCAM arranges the experimental data on the basis of the a3 selected in the $3^{\text {rd }}$ step and decides the conditions of Fuzzy rules by repeating the $1^{\text {st }}$ step $\sim$ the $3^{\text {rd }}$ step. At this time, the FCAM selects the conditions of Fuzzy whose Support is less than 0.35 .

[The $5^{\text {th }}$ step] After the FCAM selects the rule condition of each Fuzzy Rule in this way, it generates a Fuzzy Rule and stores it in the database. Because the Fuzzy Rule
Table 5. The rules of the improved C4.5 and the FRCS algorithm

\begin{tabular}{|c|c|}
\hline \multirow{7}{*}{$\begin{array}{l}\text { Improved } \\
\text { C4.5 }\end{array}$} & if(a10>=1.7) then a14=y \\
\hline & if $(\mathrm{a} 10<1.7$ and $\mathrm{a} 13<4.5)$ then $\mathrm{a} 14=\mathrm{n}$ \\
\hline & if(a10<1.7 and $\mathrm{a} 13>=4.5$ and $\mathrm{a} 5<211.5)$ then $\mathrm{a} 14=\mathrm{n}$ \\
\hline & $\begin{array}{l}\text { if }(\mathrm{a} 10<1.7 \text { and } \mathrm{a} 13>=4.5 \text { and } \mathrm{a} 5>=211.5 \text { and } \mathrm{a} 4>=122) \text { then } \\
\text { a14=y }\end{array}$ \\
\hline & $\begin{array}{l}\text { if }(\mathrm{a} 10<1.7 \text { and } \mathrm{a} 13>=4.5 \text { and } \mathrm{a} 5<211.5 \text { and } \mathrm{a} 4<122 \text { and } \\
\mathrm{a} 8<145.5) \text { then } \mathrm{a} 14=\mathrm{y}\end{array}$ \\
\hline & $\begin{array}{l}\text { if }(\mathrm{a} 10<1.7 \text { and } \mathrm{a} 13>=4.5 \text { and } \mathrm{a} 5<211.5 \text { and } \mathrm{a} 4<122 \text { and } \\
\mathrm{a} 8>=145.5 \text { and } \mathrm{a} 3<3.5) \text { then } \mathrm{a} 14=\mathrm{n}\end{array}$ \\
\hline & $\begin{array}{l}\text { if }(a 10<1.7 \text { and } a 13>=4.5 \text { and } a 5<211.5 \text { and } a 4<122 \text { and } \\
a 8>=145.5 \text { and } a 3>=3.5) \text { then } a 14=y\end{array}$ \\
\hline \multirow{6}{*}{ FRCS } & if $(\mathrm{a} 13<=4$ and $\mathrm{a} 3<=3)$ then $\mathrm{a} 14=\mathrm{n}$ \\
\hline & if $(\mathrm{a} 13<=4$ and $\mathrm{a} 3>3$ and $\mathrm{a} 12<1)$ then $\mathrm{a} 14=\mathrm{n}$ \\
\hline & if $(\mathrm{a} 13<=4$ and $\mathrm{a} 3>3$ and $\mathrm{a} 12>=1)$ then $\mathrm{a} 14=\mathrm{y}$ \\
\hline & if $(\mathrm{a} 13>4$ and $\mathrm{a} 12>=1)$ then $\mathrm{a} 14=\mathrm{y}$ \\
\hline & if $(\mathrm{a} 13>4$ and $\mathrm{a} 12<1$ and $\mathrm{a} 9=0)$ then $\mathrm{a} 14=\mathrm{n}$ \\
\hline & if $(\mathrm{a} 13>4$ and $\mathrm{a} 12<1$ and $\mathrm{a} 9=1)$ then $\mathrm{a} 14=\mathrm{y}$ \\
\hline \multicolumn{2}{|r|}{ If $\left(\frac{\mathrm{a} 13<=4}{}\right.$ and $\frac{\mathrm{a} 3>3}{}$ and $\left.\frac{\mathrm{a} 12<1}{}\right)$ then $\mathrm{a} 14=\mathrm{n}$} \\
\hline \multicolumn{2}{|r|}{$\begin{array}{lll}1^{\text {st }} \text { rule condition } & 2^{\text {nd }} \text { rule condition } \quad 3^{\text {rd }} \text { rule condition } \\
\end{array}$} \\
\hline
\end{tabular}

Fig. 7. The example of fuzzy rules

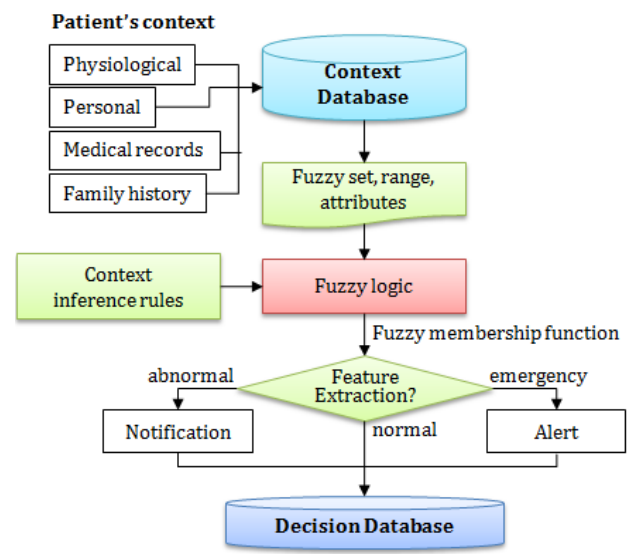

Fig. 8. The flowchart of the FDRM

generated by the FRCS algorithm is selected by computing the Conditional Support among each attribute, their accuracy is greater than that generated by the Improved C4.5 algorithm.

The rules generated by the Improved $\mathrm{C} 4.5$ algorithm and the FRCS algorithm are summarized in Table 5.

\subsection{Fuzzy-based disease reasoning module (FDRM) design}

The Fuzzy-based Disease Reasoning Module (FDRM) reasons a patient's disease by using the Fuzzy Set, Context-Awareness and Fuzzy Rules. Fig. 8 shows the total flowchart of the FDRM.

[The $1^{\text {st }}$ step] The FDRM applies the Fuzzy Set, range, linguistic variables and the Fuzzy Rules to Fuzzy Logic.

[The $2^{\text {nd }}$ step] The Fuzzy Logic generates a membership 
Table 6. Defuzzification

\begin{tabular}{c|c}
\hline Operation & Formulae \\
\hline Right most maximum & $\mathrm{U}=\sup \left(\mathrm{u}^{\prime}\right), \mu(\mathrm{u})=\sup (\mu(\mathrm{u}))$ \\
\hline Left most minimum & $\mathrm{U}=\inf \left(\mathrm{u}^{\prime}\right), \mu\left(\mathrm{u}^{\prime}\right)=\sup (\mu(\mathrm{u}))$ \\
\hline $\begin{array}{c}\text { Center of } \\
\text { Area(Gravity) }\end{array}$ & $\mathrm{U}=\frac{\int_{\min }^{\max } \mathrm{u} \cdot \mu(\mathrm{u}) \mathrm{du}}{\int_{\min }^{\max } \mu(\mathrm{u}) \mathrm{du}}$ \\
\hline
\end{tabular}

IF (ST_depression is hypertrophy) and (Blood pressure is high) then heart_disease is present)

Fig. 9. Fuzzy Rule (ST depression and Blood pressure)

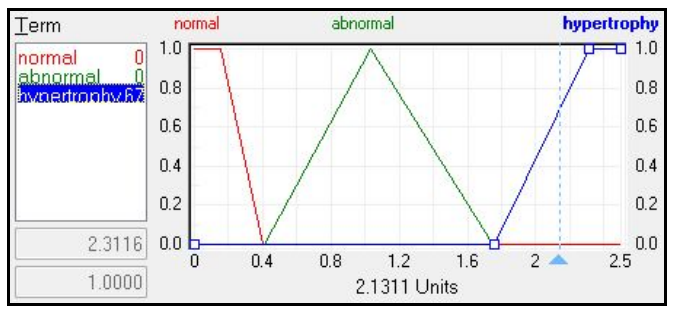

(a) ST depression $=2.1311, \max =67$

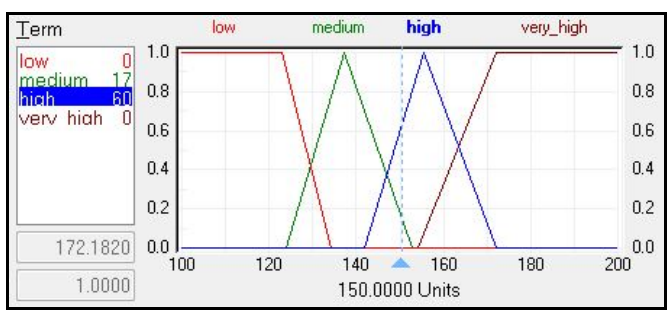

(b)Blood pressure $=150, \max =60$

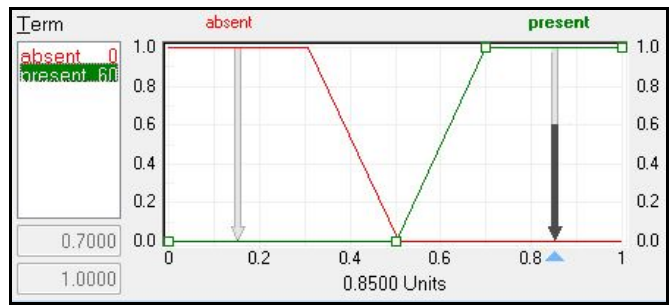

(c) output, $\min =60$, Gravity $=0.8500$

Fig. 10. The result after processing FDRM

function with Fuzzy set, range, and linguistic variables.

[The $3^{\text {rd }}$ step] The FDRM assigns a patient's ContextAwareness information to the membership function and converts the result to Fuzzy value.

For example, in case the ST depression and blood pressure of Bob is 2.1311 and 150 each, he has the Fuzzy value of Fig. 10(a) and (b).

[The $4^{\text {th }}$ step] The FDRM estimates the Fuzzy Rule of Fig. 9 and prints out the result value like Fig. 10(c).

[The $5^{\text {th }}$ step] The FDRM computes a disease reasoning value about a patient's Context-Awareness information by using the defuzzification formulae [12] of Table 6.
[The $6^{\text {th }}$ step] The FDRM notifies patients of the health information according to the computed result value. If the patient's health condition is abnormal, it prevents a patient from an unexpected disease beforehand by transferring the information to him rapidly.

\section{Analysis}

The FCAM and FDRM proposed in this paper are estimated based on the accuracy of Fuzzy Rules and Disease Reasoning by using the experimental data of Heart Disease [25].

\subsection{The accuracy estimation for fuzzy rules}

The Heart Disease consists of 14 attributes and the explanation about each attribute is shown in the Table 2 . This experimental data is made up of total 270 data and the Fuzzy Rules are generated with the 270 .

Table 7. The comparison of the FRCS and the Improved C4.5 algorithm

(a) The number of rule and rule attributes

\begin{tabular}{c|c|c|c|c}
\hline \multirow{2}{*}{ Data Set } & \multicolumn{2}{|c|}{ The number of rule Attributes } & \multicolumn{2}{c}{ The number of rules } \\
\cline { 2 - 5 } & $\mathrm{C} 4.5$ & FRCS & C4.5 & FRCS \\
\hline Training data & 6 & 4 & 7 & 6 \\
\hline
\end{tabular}

(b) The comparison of accuracy

\begin{tabular}{c|c|c|c}
\hline \multirow{2}{*}{ Data Set } & \multirow{2}{*}{ Tuples } & \multicolumn{2}{|c}{ Accuracy } \\
\cline { 3 - 4 } & & C4.5 & FRCS \\
\hline Training data & 270 & 0.82 & 0.86 \\
\hline \multirow{4}{*}{ Testing data } & 50 & 0.82 & 0.82 \\
\cline { 2 - 4 } & 100 & 0.79 & 0.83 \\
\cline { 2 - 4 } & 150 & 0.81 & 0.85 \\
\cline { 2 - 4 } & 200 & 0.80 & 0.85 \\
\cline { 2 - 4 } & 250 & 0.83 & 0.86 \\
\cline { 2 - 4 } & Average & 0.81 & 0.84 \\
\hline
\end{tabular}

Table 8. Fuzzy reasoning rules

\begin{tabular}{|c|c|}
\hline Rule 1 & $\begin{array}{l}\text { if(Thallium is low) and (Chest_pain is typical_angina) then } \\
\text { (Heart_disease is absent) }\end{array}$ \\
\hline Rule 2 & $\begin{array}{l}\text { if(Thallium is low) and (Chest_pain is atypical_angina) then } \\
\text { (Heart_disease is absent) }\end{array}$ \\
\hline Rule 3 & $\begin{array}{l}\text { if(Thallium is low) and (Chest_pain is non_angina) then } \\
\text { (Heart_disease is absent) }\end{array}$ \\
\hline Rule 4 & $\begin{array}{l}\text { if(Thallium is low) and (Chest_pain is asymptomatic) and } \\
\text { (Vessel is low) then (Heart_disease is absent) }\end{array}$ \\
\hline Rule 5 & $\begin{array}{l}\text { if(Thallium is low) and (Chest_pain is asymptomatic) and } \\
\text { (Vessel is high) then (Heart_disease is present_2) }\end{array}$ \\
\hline Rule 6 & $\begin{array}{l}\text { if(Thallium is high) and (vessel is low) and (angina is no) } \\
\text { then (Heart_disease is absent) }\end{array}$ \\
\hline Rule 7 & $\begin{array}{l}\text { if(Thallium is high) and (vessel is low) and (angina is yes) } \\
\text { then (Heart_disease is present_2) }\end{array}$ \\
\hline Rule 8 & $\begin{array}{l}\text { if(Thallium is high) and (vessel is low) then } \\
\text { (Heart_disease is present_2) }\end{array}$ \\
\hline Rule 9 & if(family_history is true) then (Heart_disease is present_1) \\
\hline Rule 10 & if(medical_record is true) then (Heart_disease is present_1) \\
\hline Rule 11 & $\begin{array}{l}\text { if(family_history is ture) and (medical_record is ture) then } \\
\text { (Heart_disease is present_1) }\end{array}$ \\
\hline
\end{tabular}


Consequently, as shown in the Table 7 , the number of the decision rules generated by the FRCS and the Improved C4.5 algorithm each is 6 and 7. This paper estimates the accuracy in comparison with the rules generated by the Improved C4.5 and the FRCS algorithm using SIPINA mining tool [26]. The Table 7 shows the estimated result. The number of the attributes used in the FRCS is smaller than that of the Improved C4.5, but the FRCS algorithm is more accurate. Therefore, it is concluded that the FRCS is more excellent than the Improved C4.5.

Fig. 11 shows the rule accuracy between Improved C4.5 and FRCS. The accuracy of rules is better if the gap in the graph is narrower. Therefore, Fig. 11 (b) shows that the rule accuracy of FRCS is the higher.

\subsection{The accuracy estimation for disease reasoning}

Table 8 shows that the rules generated by the FRCR

Table 9. Fuzzy set of heart disease

\begin{tabular}{c|c}
\hline Output & Range \\
\hline & $<0.5$ \\
Heart_disease & $0.4-0.6$ \\
& $>0.5$ \\
\hline
\end{tabular}

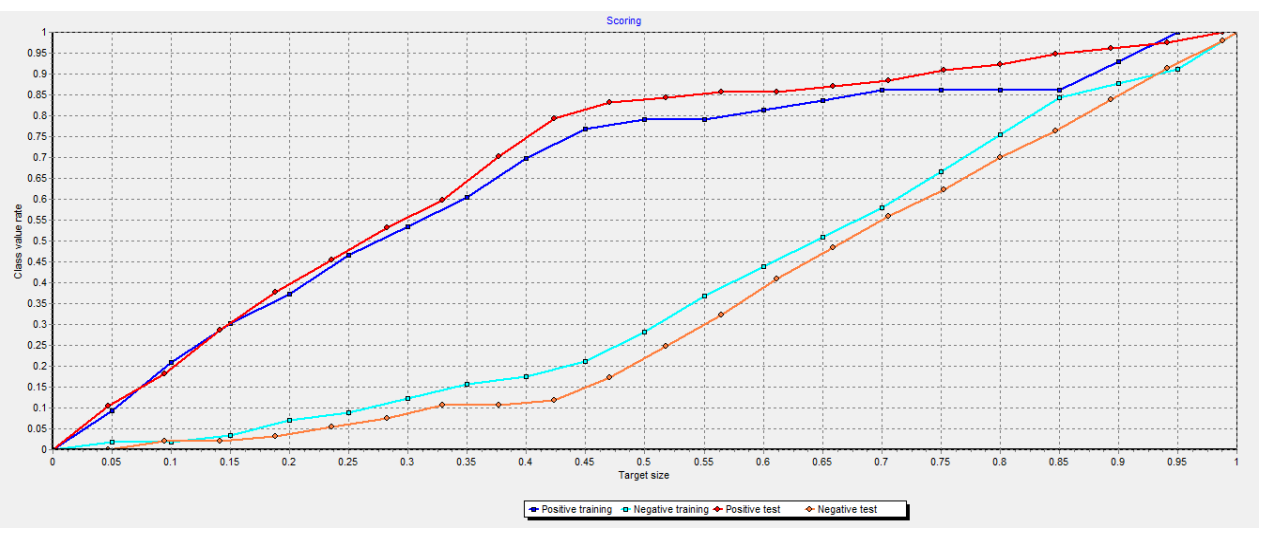

(a) Improved C4.5

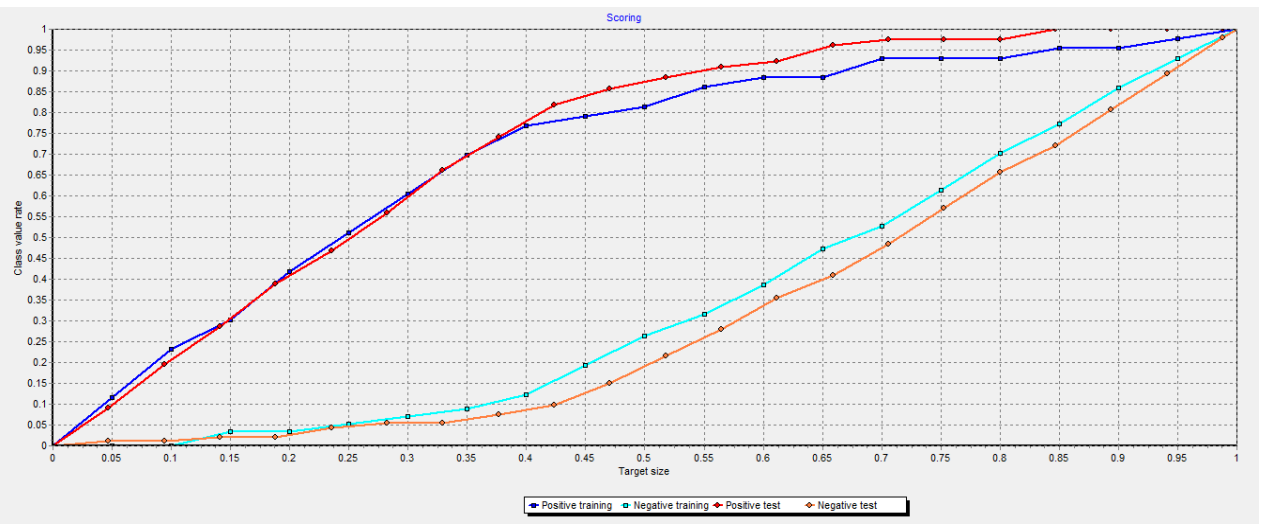

(b) FRCS

Fig. 11. The comparison of their accuracy

Table 10. Experimental data and reasoning result

\begin{tabular}{|c|c|c|c|c|c|c|c|c|c|}
\hline no & Thallium & Chest pain & Vessels & Angina & Family history & Medical Record & Heart Disease & Inference results & Success /Fail \\
\hline 1 & 3 & 4 & 0 & 0 & 0.3 & 0 & $\mathrm{~N}$ & 0.29 & S (absent) \\
\hline 2 & 3 & 1 & 0 & 0 & 0 & 0 & $\mathrm{~N}$ & 0.15 & S (absent) \\
\hline 3 & 7 & 4 & 0 & 1 & 0 & 0.5 & $\mathrm{Y}$ & 0.68 & $\mathrm{~S}$ (present_2) \\
\hline 4 & 3 & 3 & 0 & 0 & 0 & 0.3 & $\mathrm{~N}$ & 0.29 & $\mathrm{~S}$ (absent) \\
\hline 5 & 3 & 2 & 0 & 0 & 0.5 & 0 & $\mathrm{~N}$ & 0.38 & S (absent) \\
\hline 6 & 7 & 3 & 0 & 1 & 0 & 0 & $\mathrm{Y}$ & 0.83 & $\mathrm{~S}$ (present 2) \\
\hline 7 & 3 & 4 & 0 & 0 & 0 & 0 & $\mathrm{Y}$ & 0.15 & $\mathrm{~F}$ (absent) \\
\hline 8 & 7 & 1 & 0 & 1 & 0.3 & 0 & $\mathrm{~N}$ & 0.80 & F (present_2) \\
\hline 9 & 3 & 4 & 2 & 0 & 0 & 0 & $\mathrm{~N}$ & 0.37 & S (absent) \\
\hline 10 & 3 & 3 & 0 & 0 & 0.7 & 0.3 & $\mathrm{Y}$ & 0.47 & $\mathrm{~S}$ (present_1) \\
\hline
\end{tabular}




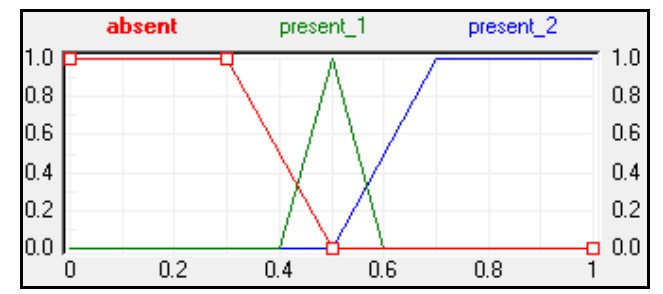

Fig. 12. Fuzzification of Heart_disease

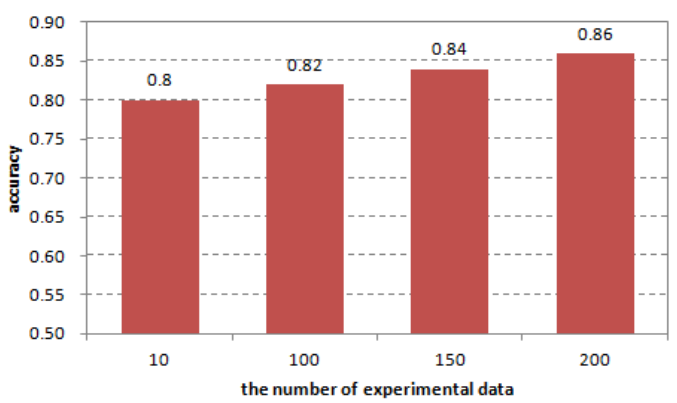

Fig. 13. The accuracy estimation according to the number of experimental data

algorithm were converted to the linguistic variables of Fuzzy Set. The rules made out of family history and medical records were added to the Table 8 .

Table 9 shows the Fuzzy Set on heart disease as a result of a disease reasoning rule, and Fig. 12 shows the fuzzification of heart disease.

The Accuracy of Disease Reasoning was estimated with the randomly extracted 10 values of Heart Disease data.

The result shows that the accuracy of Disease Reasoning in the FDRM is $80 \%$. The accuracy estimation is done by applying the randomly selected values of experimental data [25] to the Fuzzy rules of Table 8. The accuracy is computed by using expression (5)

$$
\text { Accuracy }(\%)=\frac{\text { the number of data }}{\text { the number of experimental data }} \times 100
$$

where, the number of data means the result which is true in comparison.

Therefore, when the number of experimental data is 200 , the accuracy of Disease Reasoning in the FDRM is $86 \%$.

As shown in Fig. 13, as the number of experimental data gets increased, the accuracy of Reasoning gets better.

\section{Conclusion}

This paper proposes Context-Awareness Healthcare for Disease Reasoning based on Fuzzy Logic. It consists of the Fuzzy-based Context-Awareness Module (FCAM) and the Fuzzy-based Disease Reasoning Module (FDRM).

The FCAM collects the Context-Awareness information such as physiological information, medical records, family history, etc and manages a patient's disease and the FDRM prevents a patient's disease by reasoning his disease with the information of the FCAM.

The FCAM and the FDRM have the following characteristics.

First, the FCAM manages patient's diseases by rapidly notifying a patient of his health condition after fuzzifying his collected Context-Awareness information.

Second, the FCAM computes the Correlation coefficient and Support between Condition attribute and Decision attribute. The FRCR algorithm generates Fuzzy Rules by using the attributes whose Correlation coefficient and Support are high and strengthens the relation between attributes, contrary to the Improved C4.5 algorithm. Therefore, the FRCR algorithm decreases the number of attributes used for Fuzzy Rules more than the Improved C4.5 algorithm and improves the accuracy of rules more.

Third, the FDRM reasons a patient's disease by using disease information, Fuzzy Set, Fuzzy Rule and predicts a patient's disease by the reasoning result

\section{Acknowledgements}

This work was supported by research fund of Catholic Kwandong University (CKURF-201407130001).

\section{References}

[1] Blum R. L., "Displaying clinical data from a timeoriented database," Computers in Biology and Medicine, vol.11, no.4, pp. 197-210, 1981.

[2] Hojker S. KI, Jauk A., Fidler V. and Porenta M., "Expert system's development in the management of thyroid diseases," Paper presented at: European Congress for Nuclear Medicine, Milano, Sep., 1988.

[3] Horn W., "AI in medicine on its way from knowledge-intensive to data-intensive systems," Artificial Intelligence in Medicine, vol.23, no.1, pp. 5-12, 2001.

[4] Quinlan R. CP, Horn KA and Lazarus L., "Inductive knowledge acquisition: a case study. In: JR Q.," Applications of expert systems. Boston: AddisonWesley, pp. 137-156, 1987.

[5] Zupan B. and Dzeroski S., "Acquiring background knowledge for machine learning using function decomposition: a case study in rheumatology," Artificial Intelligence Medicine, vol.14, no.1-2, pp. 101-117, 1998.

[6] Cohen ME and Hudson DL, "Neural network models for biosignal analysis," Conference Proceeding IEEE Engineering in Medicine Biology Society, vol. 1, pp. 3537-3540, 2006.

[7] Chun FK, Karakiewicz PI, Briganti A., Walz J, Kattan MW, Huland H and Graefen M., "A critical appraisal of logistic regression-based nomograms, 
artificial neural networks, classification and regressiontree models, lookup tables and risk-group stratification models for prostate cancer," BJU International, vol. 99, no. 4, pp. 794-800, 2007.

[8] Lee SM and Park RW, "Basic Concepts and Principles of Data Mining in Clinical Practice," Journal of Korea Society Medical Informatics, vol. 15, no. 2, pp. 175-189, 2009.

[9] Zadeh LA, "Fuzzy set," Information and Control, vol. 8, pp. 338-353, 1965.

[10] A Short Fuzzy Logic Tutorial, Available athttp:// cs. bilkent.edu.tr/ zeynep/files/short_fuzzy_logic_tutoria l.pdf.

[11] Mendel J., "Fuzzy logic systems for engineering: a tutorial," proceedings of the IEEE, vol. 83, no. 3, pp. 345-377, 1995.

[12] Defuzzification formular Fuzzy control programming, Technical report, International Electrotechnical Commision, 1997.

[13] Nitin K. Dhote† and J. B. Helonde, "Improvement in Transformer Diagnosis by DGA using Fuzzy Logic", J Electr Eng Technol, vol. 9, no. 2, pp. 615-621, 2014.

[14] Brown PJ, Bovey JD and Chen X., "Context-Aware Applications: From the Laboratory to the Marketplace," IEEE Personal Communications, vol. 4, no. 5, pp. 58-64, 1997.

[15] Ryan N., Pascoe J. and Morse D., "Enhanced Reality Fieldwork: the Context-Aware Archaeological Assistant," Gaffney,V., van Leusen, M., Exxon, S. (eds.), Computer Applications in Archaeology, 1997.

[16] Dey AK, "Context-Aware Computing: The CyberDesk Project," AAAI 1998 Spring Symposium on Intelligent Environments, Technical Report SS-98-02. pp. 51-54, 1998.

[17] Anind KD and Gregory DA, "Towards a Better Understanding of Context and Context- Awareness," Available atftp://ftp.cc.gatech.edu/pub/gvu/tr/99-22. pdf/1999.

[18] Quinlan JR, "C4.5: Programs for Machine Learning," Morgan Kaufmann Pulishers Inc, San Francisco, 1993.

[19] Quinlan JR, "Learning decision tree classifiers," ACM Computing Surveys (CSUR), vol. 28, no. 1, pp. 7172, 1996.

[20] http://en.wikipedia.org/wiki/C4.5_algorithm.

[21] Craw S, "Case Based Reasoning: Lecture 3: CBR Case-Base Indexing," Available at http://www.comp. rug.ac.uk/staff/smc/teaching/cm3016/Lecture-3-cbrindexing.ppt.

[22] Kusrini and Sri Hartati, "Implementation of C4.5 Algorithm to evaluate the cancellation possibility of new student applications at stmik amikom yogyakarta," Proceedings of the International Conference on Electrical Engineering and Informatics Institut Teknologi Bandung, Indonesia June 17-19, pp. 623-626, 2007.

[23] Rehana Parvin and Abdolreza Abhari, "Fuzzy data- base for Heart Disease Diagnosis," available at July.15 2014.

[24] Ali Adeli and Mehdi Neshat, "A Fuzzy Expert System for Heart Disease Diagnosis," Proceedings of the International MultiConference of Engineers and Computer Scientists 2010 (IMECS 2010), vol.1, Hong Kong, March 17-19, 2010.

[25] Heart disease, http://archive.ics.uci.edu/ml/machine/ learning-databases/statlog/heart/, July. 15, 2014.

[26] SIPINA mining tool, http://eric.univ-lyon2.fr/ ricco/ sipina.html , Nov. 10, 2014.

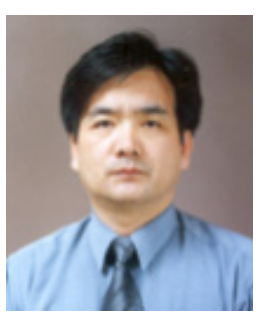

Byung-Kwan Lee He received his B.S. degree from Pusan National University in 1979, the M.S. degree in Computer Science from Chung-Ang University in 1986 and the ph.D. degree in Computer Science from Chung-Ang University in 1990 in Korea. He has been a professor of Computer Science at Catholic Kwandong University in Korea since 1988. He was a visiting professor at Saginaw Valley State university, Michigan, USA during 2000 2001. He is a permanent member of the KISS and KIPS. His current research interests are network security, Wireless Sensor Network Security, Internet of Things and Big Data.

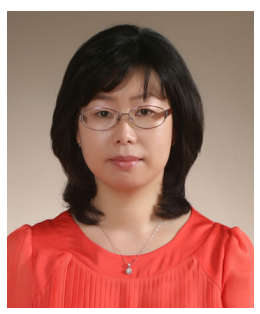

Eun-Hee Jeong She received her B.S. degree from Kangneung National University in 1991, the M.S. degree in Computer Science from Kwandong University in 1998 and the Ph.D. degree in Computer Science from Kwandong University in 2003 in Korea. She has been a professor of department of Regional Economics at Kangwon National University in Korea since 2003, Sept. She is a regular member of the KSII. Her current research interests are Sensor Network, IT security, web programming, and e-commerce security.

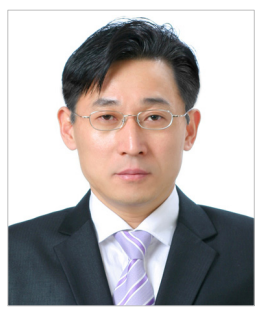

Sang-Sik Lee $\mathrm{He}$ was born in Sancheong, Korea, in 1968. In 1994 he graduated in Bio-mechatronic engineering at the Sungkyunkwan University, Korea. He received his master degree in Engineering (Mechatronics system) in 1996 and his Ph.D in 2000 from Sungkyunkwan University, Korea. He is currently an assistant professor at the college of Engineering at Catholic Kwandong University in Gangneung, Korea. His main research interests are in the area of Biomedical engineering and u-Health systems. 